\title{
Chapter 4 \\ Teachers writing cases from their own experience
}

This chapter illustrates a case-based approach for in-service teacher education and is based on the experience of one of us in the context of a post-graduate educational course for language teachers. ${ }^{10}$ We describe it and discuss its potential for promoting teacher and learner autonomy. Although our main focus is on teachers writing cases from their own action research experience, the approach also integrates the analysis of teacher-written professional narratives. An example of case construction focusing on oral reading is analysed on the basis of teachers' records of experience so as to illustrate the dynamics of pedagogical inquiry within the proposed approach.

\section{Who are we as teacher educators?}

This is perhaps the first question to ask when we talk about approaches to teacher education, since these depend largely on teacher educators' professional biographies, ideologies and aspirations. The same question is posed by Lunenberg and Hamilton (2008) to discuss how teacher educators construct their identities, and whether they are/should be consumers or producers of knowledge. The authors reflect about the vagueness of teacher education as a multi-layered profession, arguing that teacher educators must connect their personal history with practical theory and develop public knowledge through self-inquiry. They further advocate the constitution of communities of practice where teacher educators can work together to produce that knowledge.

Inquiring into our pedagogies is one way of understanding not only who we are but who we wish to be as teacher educators. A scholarship of pedagogy can make teaching community property and promote faculty development as an experience of transformation, helping them reshape their identity and practice (Shulman 2004b). Actually, the approach we present here was initiated by Flávia in 2003 within a multidisciplinary project that involved a community of practice

10 The approach has been developed in a course that is part of a two-year MA programme on supervision and language education, at the University of Minho (Braga, Portugal). The course takes place in the first semester (15 weekly lessons of 3 hours each). Each year the programme is attended by $15-20$ schoolteachers. Teachers of French, German, English, Spanish and Portuguese can enrol in the programme. 
where teachers inquired into their own teaching. ${ }^{11}$ It was then that she decided to explore and inquire into the role of professional experience in post-graduate language teacher education. She had always acknowledged the value of educational experience in teacher development for teacher and learner autonomy in schools, but that was the first time that it became the core of her course rather than just one of its components. Based on that first exploration, she subsequently developed the approach here presented.

Developing a case-based pedagogy involved a quite significant change in her practices. It entailed starting to centre her teaching on the teachers' experience more intentionally, thus moving away from a system where teacher education practices are rather predictable as they depend mostly on the teacher educators' knowledge and choices. Another change was that she also started to inquire into her own and the teachers' practice more systematically than before, and she began to write about and disseminate her experience as a teacher educator. She feels that her involvement in the scholarship of pedagogy (SoP) in teacher education has reshaped her professional identity:

For me (...) being involved in SoP has become a moral and political imperative. If I had to sum up my experience, I would say that it has been an exciting journey of self-discovery, an emotional and intellectual challenge to become a better educator, within a more collective struggle to build re(ide)alistic practices that transform the role of pedagogy in the academic milieu. (...) It has allowed me to excavate my self - who I am and why, what I want for my students and what for, what external and internal forces constrain my theories and practices and what I can do to counteract them. (Vieira, Almeida, and Silva 2008: 632/634) ) $^{12}$

When teacher educators experience empowerment and transformation in their own professional development, they can better appreciate the fact that teachers' development should also be about empowerment and transformation. This calls our attention to the question we started with - who are we as teacher educators? - as well as to the conditions that may hamper or foster the development of our profession in our communities. We would argue that case pedagogy poses that question and can help us redefine the purposes and outcomes of teacher education pedagogy.

11 The project aimed at articulating research, pedagogy and professional development through pedagogical inquiry and the dissemination of practice (for further details, see Vieira 2009e). 12 This paper integrated the authors' personal accounts of their Scholarship of Pedagogy experience. These are excerpts from Flávia's reflections. 


\section{Exploring cases for teacher and learner autonomy}

If we believe that teacher development should be an empowering, transformative experience, then we should consider the role of knowledge in teacher education practices: What knowledge is privileged and by whom? Who produces it, how, and in whose interests? What is its social relevance? Who assesses its worth?

The promotion of teacher autonomy requires that teachers are directly involved in the (de/re)construction of professional knowledge. This knowledge is multidimensional: it is practical and theoretical, normative and uncertain, technical and moral, autobiographical and socially constructed, shaped by ideologies and also determinant for the reshaping of ideologies (Vieira 2009c, 2011b). It is also paradoxical, as it is situated between knowing what to do and accepting not to know it (Contreras 2010: 247). Therefore, its (de/re)construction is not a straightforward process. In fact, it involves a myriad of processes that need to be constructed with and by the teachers, around their professional experience, so as to create opportunities for them to appreciate the complexity of teaching as an ill-structured domain, become critical about the justifications and implications of their action, develop their ability to disclose and surpass constraints, and make decisions based on values that are conceptually and morally valid. From this perspective, teacher education programmes should enhance teachers' epistemological autonomy as they struggle for a better education in schools, thus avoiding inertia, scepticism or cynicism, which often undermine professional development and innovation.

The use of teaching cases can fulfil these purposes by enacting a pedagogy of experience (Vieira 2009b, 2010b, 2012), that is, a pedagogy that is rooted in education from, through and for experience (Dewey 1963: 29). In previous chapters, we have already pointed out the potential value of cases in teacher education. As a lingua franca in teacher development communities (L. Shulman 2004a), they can create bridges between different aspects of teacher development that are traditionally kept apart: theory and practice, knowing and doing, research and teaching, reality and ideals. Surpassing these dichotomies appears to be necessary if we are to build what Zeichner (2010b) calls a "third space" in teacher education, a space where the hegemony of academic knowledge is replaced by a combination of different kinds of knowing and where participants negotiate understandings. This negotiation involves the creation of a "third idiom" (Shor 1992), a new discourse that emerges from inquiry-oriented dialogue, standing somewhere between the academic and non-academic idioms: 
The dialogic third idiom is simultaneously concrete and conceptual, academic and conversational, critical and accessible. (...) It transforms both idioms [the teacher's and the learner's] into a new discourse, the third idiom, which relates academic language to concrete experience and colloquial discourse to critical thought. (...) This invented third idiom philosophizes experience while experientializing philosophy. As a discourse evolved in a democratic process, it rejects the unilateral transfer of culture from the teacher to the students. (...) The current academic canons of language and subject matter need to be transformed in a multicultural way with and for students, to reflect their language and conditions. (Shor 1992: 255-256)

Although Shor refers to teaching in schools, his concept also applies in teacher education contexts, where the distance between teacher educators and teachers as regards specialised knowledge often hampers dialogue and silences teachers, as if all of a sudden they lacked a language to talk about their own profession. A focus on professional experience through the use of cases opens the road for the emergence of content and language that are more "multicultural" in the sense that they incorporate different forms of knowing, and also a new form of communication that is contingent on the participation of everyone and whose major goal is negotiation for intercomprehension. Because knowledge is constructed collaboratively and is related to professional experience, teachers feel more confident and willing to participate, and they can appreciate theoretical input more fully as an instrument to reconfigure their own theories and practice. Therefore, along with other researchers, we would contend that to a large extent the value of case pedagogy is in the discussion process itself (Barnes, Christensen and Hansen 1994; Flyn and Klein 2001; Merseth 1991b; Richardson 1991; Welty 1989).

The approach we describe below integrates case analysis and case construction. At the beginning of the course, the teacher educator explains the rationale of the approach and case analysis is initiated so that a focus on professional experience is ensured and theoretical input can be related to it in a systematic way. Not much later, teachers start to design a pedagogical experiment that is the core of case construction. This involves planning, implementing, evaluating and narrating the experiment. Case analysis and case construction develop simultaneously and feed into each other in productive ways. A brief description of how they unfold is given below.

\subsection{Case analysis}

In case analysis, teachers are guided in the interpretation of professional narratives (of about 15-20 pages) produced in previous years by other teachers within case construction in the same course (see section 2.2 below). Those narratives 
illustrate pedagogical experiments of pedagogy for autonomy in language education and provide useful examples of what is expected from teachers in the construction of their own cases. ${ }^{13}$

Different frames of reference are used for analysis, emerging from the teachers' own experience and personal theories, and also from theoretical input provided by the teacher educator, so that they can explore answers to the question "what is this a case of?" (L. Shulman, 2004a). In trying to answer it, teachers appreciate the authors' experience from different angles and expand their own professional knowledge in diverse directions. The role of the teacher educator is to facilitate reflection and dialogue, question tacit beliefs and assumptions, provide alternative points of view, and expand theoretical knowledge.

Case analysis begins in a rather unstructured fashion, focussing on what the teachers found most relevant after their first reading of the narrative. Dialogue is encouraged, usually starting with a very general question such as: "What would you like to say about this pedagogical experiment?" Collaborative reflection proceeds in a quite unpredictable way as the main purpose of this first reading is to begin establishing connections between the narrative and the teachers' personal theories and experience. As the narrative is discussed, the teachers' tacit assumptions and beliefs begin to emerge and become the focus of reflective dialogue. Cognitive dissonance begins to unfold as different perspectives are confronted and teachers start to question their own ideas and practices in the light of both the narrative input and its collective discussion. The teacher educator needs to be attentive to everything that is said so that s/he can instigate critical reflection and support non-judgemental interaction whereby participants begin to excavate their own selves. Asking questions about what is said is of paramount importance: "Why do you say that...?”, “Can you give an a example of...?”, “How does.... relate to....?”, "What are the implications of...?”, "Why does... occur?”, "What if...?”. Everyone's opinions are seen as valid contributions for collective reflection and no unique understandings are sought. Rather than reaching consensus, it is important to promote divergent thinking and the confrontation of perspectives.

After this first stage of analysis, teachers are provided with theoretical input that can support more oriented re-readings of the narrative or parts of it, often in

13 When the approach was implemented for the first time in 2003, theses narratives did not exist and other narratives were used, namely teacher narratives published by members of the GT-PA Grupo de Trabalho-Pedagogia para a Autonomia/ Working Group-Pedagogy for Autonomy (see Vieira 2009d). Narratives published in English on the promotion of autonomy can be found in the literature (e.g. Sinclair, McGrath, and Lamb 2000; Barfield and Nix 2003; Barfield and Alvarado 2013; Palfreyman and Smith 2003; Barfield and Brown 2007; Jiménez Raya and Lamb 2008a; Kalaja, Menezes, and Barcelos 2008). 
groups before collective discussion, with the aim of exploring focused answers to the question: "what is this a case of?". Narratives always include their authors' own answers, but these can be questioned and expanded, depending on the frameworks of reference used. As L. Shulman puts it, "Were it grammatically correct, I would prefer asking the question 'what are this a case of?'”(2004a: 467).

The role of theoretical input (which can be purely theoretical or based on empirical studies) is to expand teachers' horizons as regards teacher/ learner empowerment and develop their ability to scrutinise experience. In this particular course, they are asked to read texts focusing on a constructivist approach to education, democratic education and pedagogy for autonomy, reflective teacher education (including case-based pedagogy), and teacher inquiry. Apart from the texts that support case analysis directly, other texts are recommended to expand knowledge. Theoretical input is always discussed in class and teachers have the opportunity to raise any issue they find relevant - what surprised them, what they could (not) relate to their own ideas and practice, what they could (not) fully understand or appreciate, etc.

Frames of reference for the analysis of narratives are selected on the basis of what the teacher educator finds more relevant at a particular moment in the development of the course. One or more inputs can be provided and used sequentially, depending on the time s/he wants to spend with each narrative. Instead of full texts, excerpts of texts and reflective tools can also be used, like the example below, based on Jiménez Raya, Lamb and Vieira (2007: 54), which can help teachers analyse the extent to which a particular narrative/ pedagogical experiment is a case of centring teaching on learning, a central requisite of pedagogy for autonomy.

\section{Centring teaching on learning}

Does the experiment...

- Foster the learners' self-esteem and willingness to assume responsibility for learning?

- Involve the learners in reflection about language and the language learning process?

- Foster knowledge of and experimentation with language learning strategies (in/outside class)?

- Foster (self/co-)management of learning activities (planning, monitoring and evaluation)?

- Foster the negotiation of ideas and decisions with and among learners?

- Encourage cooperation and team work among learners?

- Enhance the formative role of (self-)evaluation and (self-)assessment? 
- Integrate the collection and analysis of learner data so as to understand and improve teaching?

- Encourage learners to collect and analyse data so as to understand strengths and weaknesses?

By relating a particular framework with the narrative/ experiment at hand, teachers also discuss their own understandings of the framework and how it connects with their personal experience. At this stage, the teacher educator expands and clarifies theoretical input. Again, s/he must conduct the dialogue so as to promote critical reflection and encourage participation and the negotiation of perspectives. Interaction continues to be quite unpredictable, although more oriented towards the exploration of particular views and practices of language education. Everyone's opinions are valid contributions for collective reflection, but reaching some consensus becomes important as regards theoretical understandings and how they apply to the case.

In scrutinising narratives from different angles, teachers theorise practice, expand professional knowledge, revise their own experience, and complexify their views of teaching and learning. Because the narratives illustrate inquiryoriented pedagogy, they also begin to appreciate the value of teacher inquiry for teacher and learner empowerment, and become increasingly aware of their own role as potential agents of change.

All the processes involved in case analysis contribute greatly to (de/re)construct teachers' professional knowledge. However, giving teachers the opportunity to plan and enact change is necessary to expand those processes further. This is the goal of case construction, where teachers become authors of autonomy stories.

\subsection{Case construction}

In case construction, which starts shortly after the course begins, teachers are guided in the design of small-scale, collaborative action research experiments aimed at promoting pedagogy for autonomy, which they carry out in the classroom (one teacher per group, in one class). Classroom data for analysing and evaluating experiments can be collected in many different ways (e.g. observation, reflective records, questionnaires, learner assignments, etc.). In interpreting and narrating those experiments, teachers try to answer the question "what is this a case of?" by triangulating personal theories, theoretical input and classroom data. 
For designing the pedagogical experiments, a set of guiding questions that ensure an action research approach is provided:

- What interest, dilemma, problem, concern... would we like to explore? Why?

- What are the purposes of inquiry?

- What is the context for experimentation? (participants, previous experience...)

- What action strategies might be useful? What materials/ resources will be needed?

- Who participates in the evaluation of the experiment and what data collection strategies/ instruments might be used to evaluate it?

- What impact can the experiment have on teacher and learner development?

- What readings will be needed? About what and for what?

- What vision of education underlies the experiment?

The designing phase is supported by the teacher educator in class and through e-mail. This includes giving feedback to the teachers' plans and data collection materials, as well as suggesting readings about the topics they choose to explore. Each experiment should involve around 2-3 lessons at school, taught by one teacher in each group and observed by colleagues whenever possible. By making experiments collaborative and reducing their number, the teacher educator's support increases, cooperative learning is encouraged, and the quality of experiments and narratives is enhanced. ${ }^{14}$

Deciding on the focus of pedagogical inquiry engages teachers in thorough discussions about their concerns regarding language teaching and learning (e.g Why do students resist oral participation in class? How can they be helped to develop more creative writing? Why are they so demotivated in class?...). Choosing a topic takes time and is not always easy as group members may have different experiences and opinions about what is worth exploring. Even when they reach a consensus, the problems they set are not always clearly framed and need to be discussed with the teacher educator so that the objectives and strategies of inquiry are consistent, feasible, and related to valid educational purposes. On the other hand, the connection between their concerns and learner autonomy are not always straightforward, since most teachers lack previous experience of

14 When the approach was explored for the first time, all teachers were asked to develop individual small-scale experiments during the course. Even though the overall evaluation of that approach was quite positive, it also showed that there was no time for the teacher educator to support the design of all the experiments, collaboration among teachers was low, and the resulting narratives were too short and sometimes not critical enough. 
autonomy in the classroom. Another difficulty relates to data collection. Teachers are rarely used to evaluating their action, so their first tendency is to separate teaching from research strategies. On the contrary, data collection strategies and instruments should have both a pedagogical and a research purpose so that inquiry can be used in the service of pedagogy. For example, if they want to explore a particular language skill and an initial questionnaire is used to collect the students' perceptions of attitudes and competences regarding it, the students' answers should be later discussed in class so as to increase learning awareness and pave the way for future learning activities.

Acknowledging and surpassing this kind of difficulties are part of professional growth and this is why the planning phase takes time. Teachers need time to read, to revise plans and materials, and to become aware of justifications and implications of their choices. The teacher educator needs time to discuss and elaborate their ideas, give practical suggestions and provide examples, revise materials, and propose readings. Actually, the whole strategy requires the creation of "public time", that is, time spent in reflective dialogue and negotiation of perspectives and decisions, and not "entrepreneurial time", that is, accelerated time used to fulfil instrumental objectives whose rationale is not questioned (Giroux 2007).

The phases of implementation, analysis and narrative writing are conducted by the groups with no direct interference from the teacher educator. Because planning is thoroughly discussed and supported, conditions are created for the teachers to act more independently. Moreover, teacher empowerment necessarily entails learning to manage insecurities, uncertainty and dilemmas, both individually and cooperatively. On the other hand, case analysis supports case construction as regards the integration of theory and practice, data analysis and narrative writing.

Group narratives (of about 15-20 pages) should be written in a personal style that combines the rigorous analysis of experience with the integration of theoretical knowledge and the use creative language (analogies, metaphors...). They should be examples of writing from the self rather than about the self (Contreras and Pérez de Lara 2010), ensuring that the writers' stance is both close to lived experience and critically detached from it, and giving potential readers the opportunity to learn from it. Writing is seen not as an instrument to report on what happened but rather as a method of (self)inquiry whereby teachers construct understandings of pedagogy as an ineffable phenomenon (Van Manen 1990).

The narratives of autonomy experiments are assessed by the groups and the teacher educator as regards intelligibility, situational relevance, the quality of teaching approaches, criticality, integration of theoretical knowledge, rigour, and clarity of language. After assessment, groups are invited to revise their narratives 
on the basis of the teacher educator's written feedback, and permission is asked to use the revised versions with other teachers for case analysis as well as for research and publication purposes. This is the reason why it has been possible to use the teachers' narratives for case analysis as described in section 2.1 above.

Teachers are also encouraged to disseminate pedagogical experiments in schools and professional conferences, and some have done it. Sometimes, their experiments open up possibilities for further exploration within their master dissertations, either through more extensive action research studies or through descriptive studies that focus on autonomy-oriented practices.

In the approach suggested here, teacher educators seek to use their power to empower teachers, providing opportunities for and supporting self-directed development. We hope that this becomes more evident in the following section, where a teacher-constructed case is analysed.

\section{Building cases from inquiry into experience}

In this section we illustrate the process of case construction by drawing on a pedagogical experiment focussed on oral reading in the English classroom, conducted by a group of four secondary schoolteachers (Teixeira et al. 2010). Through the analysis of that process, illustrated with excerpts from their narrative and other elements of their course portfolio, we hope to show how teacher inquiry and writing from experience can empower teachers to pursue teacher and learner autonomy in language education. ${ }^{15}$

\subsection{Getting started: defining the focus and purpose of peda- gogical inquiry}

When teachers realise that their teaching is unsatisfactory and decide to move towards more learner-centred pedagogy, they are aware that their path is uncertain but they are also determined to challenge established regimes and subvert current practices. As this group of teachers wrote in the introduction to their port-

15 Permission was given by the teachers to use excerpts of their narrative and other elements from their course portfolio. The course portfolio integrates the narrative and other support documents, as well as an introduction and a reflective evaluation of the course. All excerpts presented here are translated from Portuguese, including some of the students' interventions quoted from class interaction. The present section builds on a previous (shorter) analysis of the same narrative (see Vieira 2010b). 
folio, "by rejecting conformity and facing uncertainty, dilemmas and tensions, with a lot of persistence and effort, we chose to break with the limits of our everyday life and let subversion cross our sinuous way." They somehow "get off the rails", as Schostak suggests when he talks about enacting change in schools: "If a formal curriculum is imagined as being like a chariot race where competitors go round and round in circles until some arbitrary finishing point is reached, then deliberate crashes, derailings or simply stopping and not playing the game become the only real challenges to the system" (Schostak 2000: 37).

Getting off the rails becomes a way of struggling for teacher and student empowerment by rejecting a position of subjugation to authority and reclaiming the right to direct pedagogical action. However, developing a self-directed, inquiry-oriented approach towards more democratic teaching is not a straightforward process. In the introduction to their portfolio, these teachers also write about their lack of experience "in looking at teaching as an act of inquiry" and how they started "with a lot of worries and uncertainties" that decreased progressively as they began "visualising a relevant, coherent path that presupposed the integration of theory and practice, based on processes of negotiation, in which the teacher educator's role began to fade away as [their] transformation as teachers-learners became visible".

Conversations with teachers during the stage of deciding on a focus for inquiry show that they are often unsatisfied with their teaching and eager to learn about alternative strategies, but they also feel unprepared to do it and disempowered by a school culture that stifles autonomy. Along with Kincheloe (2003: 2), we can say that "teachers understand that something is not right". As they begin to disclose silenced beliefs and desires, but also criticisms, fears and anxieties, they become painfully aware of the gap between "espoused theories" and "theoriesin-action" (Argyris and Schön 1974), which may generate feelings of insecurity and uneasiness. As L. Shulman (1992) puts it, pedagogy starts with frustration, that is, an awareness that something is wrong and needs to be changed.

This group of teachers decided to develop an experiment on oral reading in the English classroom because they were often confronted with their students' attitudes of resistance to this practice. They began to question the reasons why that happened and how that situation might be changed. In dialogue with the teacher educator, they eventually realised that the most usual routines for oral reading in class have no educational value whatsoever: asking the students, one by one, to read a text (any kind of text) by chunks as the initial step of reading comprehension tasks, and correcting some or all the pronunciation mistakes they make as they read. Furthermore, these routines are totally artificial: we can hardly find any other situation where a group of people have to read text chunks aloud without knowing the text in advance and with no other purpose than just 
reading aloud. It is easy to understand why this practice may generate feelings of uneasiness, anxiety and resistance in the students. However, none of this seemed to be evident to these teachers before they reflected about what, why and what for they did what they did.

Their narrative provides a thorough account of the rationale for a plan of action whereby they sought to transform traditional oral reading routines into a meaningful practice by making it more learner/ learning-oriented. Nevertheless, finding an area for improvement and designing an autonomy-oriented learning plan is not as easy as the teachers' narratives often seem to suggest. Actually, when the group first started to think about their focus for inquiry, oral reading was not their concern. Their starting point was quite different. They brainstormed several possibilities and wanted to experiment with new technologies in class: podcasting. One of the teachers was enthusiastic about and experienced with technology, and they all realised that students enjoy it and need to learn how to use it. However, when questioned about their pedagogical purposes, they were not clear about them, even though later on, in the introduction to their portfolio, they write that technology "would only be pedagogically useful in the service of the development of other competences". After thoughtful consideration of how this might be accomplished, the focus on oral reading competences emerged as a possibility. Podcasting could be a useful resource for students to record and listen to their readings, but was no longer the focus of their work. Furthermore, as they started to plan the learning tasks and discuss them with the teacher educator, their attention was also directed at how they might enhance the students' abilities to learn how to read. They eventually decided to raise students' awareness of oral reading difficulties and competences, and involve them in self-correction, self-evaluation, and reflection about the approach to be implemented.

In the narrative, they theorise their experiment as a case of promoting learner autonomy, stating that what interested them "was the process of each student's transformation. More important than the product (improving students' performance in expressive oral reading) was the process of developing metacognitive strategies". They also write that the experiment was a case of professional collaborative inquiry that enhanced a reflective, (self-)regulatory stance towards teaching. We can see how the development of this stance started at the planning stage, as they moved away from a rather technical view of teaching (using technology because students like it and need to learn how to use it) to a transformative view of pedagogy where their concerns with learning became the springboard for more informed, learner/ learning-centred action. Until a final plan was reached, several possibilities were discussed. As they say in the introduction to their portfolio, "the imperative of an extensive working agenda was... TRANSFORMATION. 
Like Penelope, we wove and re-wove our 'shawl': the plan, the objectives, the activities, the materials... were successively reformulated."

As suggested by Schön (1987: 4), problem setting is a form of worldmaking that requires practitioners to make sense of messy, indeterminate situations. Moving away from a technical view of teaching demands tolerance of uncertainty and ambiguity, as well as self-determination to find a plausible path of (self)discovery. Having a set of guiding questions to plan the experiments has proved to be crucial in this respect. It supports teacher reflection on various components of pedagogical inquiry, encourages thoughtful consideration of justifications and implications of choices, and facilitates dialogue with the teacher educator. As teachers write and re-write their answers to their planning guide, they reconceptualise their projects and make them more informed, more coherent, and more oriented by a democratic vision of language education.

\subsection{De-schooling professional knowledge}

The (de/re)construction of professional knowledge is a major purpose of case pedagogy. This often entails questioning and transforming ingrained ideas and practices by moving from choices based on a notion of "school knowledge" to choices based on a notion of "action knowledge" (Barnes 1976), that is, knowledge that relates to life experience. For these teachers, this became evident when they had to choose the text to use for oral reading in class, still at the planning stage:

\footnotetext{
After choosing our topic, the appropriateness of the text was another challenge. As we were not aware of what oral reading entails in scientific terms, our choices focussed on dialogues in which oral reading was just about using speech acts: At the Restaurant; Job Interview. In revising our plan, the teacher educator alerted us about the need to reconsider our choice:

'Well, you have to think this further, because an interview is NOT a type of text to be read aloud. What types of texts are liable to be read aloud? If you want to use an interactive text, it seems to me that it will have to be, for example, a theatre play... When actors perform the play they do not read because they already learnt the text by heart, but the process to get there is an oral reading process. It might also be a dialogue in a piece of literature, since reading literature aloud is also an authentic task.' (F. Vieira, feedback on plan).
}

This stage was a turning point in our own learning process. (Portfolio: Introduction)

When the teachers say this was a turning point in their learning process, they are acknowledging the fact that teacher development entails informed decision-mak- 
ing, which requires, as we have pointed out earlier, the expansion of pedagogical content knowledge (L. Shulman 1993). They needed to read and learn about (oral) reading in order to better understand how to promote it in class. At several points in their narrative, they draw on their readings to support their choices (e.g. Dawson 2000, Oakley 2003, Rennie 2003, Abromitis 2009, Marinaccio-Eckel and Donahue 2009), including the criteria used for selecting the final text: a simplified version of part of a play written in verse and related to a well-known fairy tale - Cinderella ${ }^{16}$. This choice is justified on the basis of adequacy for expressive oral reading, authenticity, relation to students' experience and appropriateness to their linguistic level. Somehow, they had de-schooled their reasoning to make a choice that was more action-oriented and educational.

Promoting action knowledge in school is important for all students, but it is particularly relevant for students who come from disadvantaged backgrounds and have learning difficulties. This was the case of the class where the teachers chose to implement their plan, a class of 11 students who were attending a vocational programme that is equivalent to the $9^{\text {th }}$ grade (level 3 of English). Students in these programmes usually have a history of school failure and low expectations regarding academic achievement. Enhancing motivation through investment in meaningful learning is thus crucial in this context.

De-schooling professional knowledge is also about imagining pedagogical approaches that subvert dominant teacher-centred practices and are more in accordance with "an exciting vision of schooling”, a vision that stresses "the role that education can play in producing a just, inclusive, democratic, and imaginative future" (Kincheloe 2003: 111). This could be observed as the teachers engaged in creative strategy planning, with the support of the teacher educator. Their intervention was radically different from their usual oral reading practice, although the first step was intentionally similar. One of the usual routines - asking students to read a text aloud with no previous preparation - was performed with the intention to subsequently raise the students' awareness of its inadequacy. The teacher arranged the students in groups, gave them a scene from the script of the play Cinderella, and asked them to read it aloud by playing different roles. This is how they describe this step as it occurred in class:

The students organize themselves into groups and the teacher asks them to read the text aloud. The incredulous actors begin and moments of "robot reading" follow, full of hesitations, It's you... No, it's you, in a slow, syncopated rhythm, with strange pronunciation... They do not question the strategy, but an effort to please is noticeable. Finally, when asked about what they did, they answer: A dialogue among characters, A theatre play, Reading...

16 Cinderella from Charles Perrault, retold by Dooley and Loyd, 2004, Berkshire: Express Publishing. 
What type of reading? one insists... They get to the idea of expressive reading. "Leitura Oral Expressiva" [Expressive Oral Reading] is written on the blackboard.

When questioned about the easiness of the first task, the actors intervene with divergent comments: Simple text, Not very long or Because we did not know the text, it was difficult. Difficulties pour in through brainstorming and they seem to begin to understand that the stage director did not freak out, all this is a new performance technique that she wants to test. When confronted with the question What is good reading? they are still staggering and uncertainty seems to hang over their minds again: Is she thinking that we have to invert roles?! Are we supposed to be the teacher/ stage director?! Then the explanation comes - You were not well instructed. Ah! The mystery starts to be disclosed, but the strategy of this play is not yet revealed: It was done on purpose, later on you will understand why. (Portfolio: Narrative)

When classroom action is described in the narrative, it is presented in the style of a play script as above, and divided into "scenes". These scenes, summarised below, correspond to three important elements of centring teaching on learning: awareness-raising, self-directed practice, and self-evaluation. They were developed in two sequential lessons of 90 minutes each.

\section{Scene 1: awareness-raising}

- In groups: students read an excerpt of the play aloud, without any previous preparation

- Brainstorming (blackboard) about Expressive Oral Reading: problems felt

- Filling in a diagram: students match problems with reading competences (intonation, expressiveness, rhythm, punctuation, pronunciation, fluency, understanding)

- Reading a set of guidelines for expressive oral reading and filling in the blank spaces with given words (e.g. Read the text (silently) before reading it aloud.)

\section{Scene 2: self-directed practice}

- In groups students prepare for oral reading by using the guidelines, dictionaries and a CD with a model reading; they record their readings, listen to them and self-correct (podcast)

- Each group presents their final recordings to the class

\section{Scene 3: self-evaluation}

- Self-evaluation of reading performance before and after the preparation strategies (the self-evaluation instrument integrates the problems pointed out by the students in scene 1 , grouped under the reading competences presented in the diagram)

- Class conversation about the whole experience 
When considering the above sequence, we can see how the students themselves, and not just the teachers, were supported to de-school their ways of knowing by becoming more directly involved in understanding what reading aloud is about, by experimenting with reading strategies, by participating in self-reflection and by evaluating the whole experiment with the teacher. This is coherent with the objectives set for the experiment:

Through this experiment we sought to develop the students' oral reading competence in a foreign language, stimulating them for that purpose; to promote their initiative, critical mind and autonomy; to develop their problem solving strategies; to promote collaborative and autonomous work in class, with the help of various resources; and to enhance their taste for oral reading. (Portfolio: Narrative)

\subsection{Students as critical consumers and creative producers of knowledge}

Learner-centredness is the core principle of pedagogy for autonomy and it can be enacted in many different ways. In this teachers' experiment it meant: incorporating the students' ideas in the teaching strategies, rather than giving them predefined information on how to learn; letting students direct their own learning; involving them in self-evaluation and the evaluation of teaching. In this way, the students were given opportunities to become critical consumers and creative producers of knowledge, rather than passive recipients of teacher knowledge (Vieira 1998).

By asking the students to read the text without any previous preparation, the ground was set for collective reflection on difficulties, competences and strategies involved in oral reading. The brainstorming activity allowed the students to voice their difficulties, which confirmed the problems previously identified by the teachers in the oral reading routine they used to follow before this project:

I was not expressive / I read in a low voice / I did not respect the punctuation

I did not say the words well / I had difficulties pronouncing the words

I did not read the text throughout / I hesitated in some words

I didn't understand the meaning of words / I had no instructions to follow

With the purpose of raising the students' awareness of oral reading competences, a diagram was presented with elements that compose those competences (into- 
nation, expressiveness, rhythm, punctuation, pronunciation, fluency, and understanding) and the students were asked to match them to the above difficulties. Students realised that oral reading is a complex activity and their difficulties may relate to different competences. Then, they were asked to reflect about strategies that could help them develop expressive oral reading abilities, and they filled in a set of guidelines (in Portuguese) they would later use to prepare for expressive oral reading:

In order to read expressively, I need to:

1. Read the text in before reading it aloud.

2. Use support techniques as I read: signal what I don't understand, consult the and write the meaning of new words, take note of unfamiliar pronunciation, etc.

3. ___ the global meaning of the text.

4. to the oral text, more than once, before reading it aloud.

5. Read it __ several times to practice expressiveness.

6. Practise oral reading in (dramatic text)

7. Train the and the through access to reading models.

8. Ask for the help of others (more fluent students/ teacher) to overcome my

* understand *dictionary * pronunciation *listen *aloud *dialogue * silence *difficulties *intonation

(Portfolio: Narrative)

After these reflective tasks, the groups started working on their own. They read the play in silence, worked together on reading comprehension, rehearsed and recorded their oral readings until they were pleased with their performance, and played their recordings for their classmates. Their involvement was extremely high and the final result was satisfying:

The students talk in a low voice, seeking to assimilate their role (...). There is a tacit agreement, no one argues: one student looks up words, another writes the translation, still another searches for its pronunciation in the computer. They read and activate mechanisms of self/co-correction without interrupting one another: 'Shame! What a terrible shame!'17, Start again, you are not using the right intonation!, Can't you respect the rules as you read?

The echo of their words instigates our reflection on the Chinese proverb: Don't give the fish, teach how to fish.

(...)

17 One of the lines in the play script. 
The audience ${ }^{18}$ does not appear for the second rehearsal and the stage manager goes on with her work, clarifying her role: to coordinate the actors. The actors do not slow down and keep on doing their best: You have to write an accent here so that you know that you have one more syllable to pronounce, Why don't you write above the word the way you pronounce it? It's easier, You always get the beginning wrong, make a note!, Remember that song by David Gueta Choose, then you know how to pronounce 'choose'...

(...)

... Applause is heard! They reflect on the faces and the voices of the students who have enthusiastically recorded and self/co-corrected their readings, now looking serious and concentrated as if in an audition... suddenly, the buzz that sometimes occurs in class as a result of group work gives place to bodies inebriated by their own voices and oral performances... Yes, the applause is deserved, with the right to a BRAVO!

The students were able to read with good proficiency, and their self-evaluation shows their awareness of progress from the initial reading to the final one (Table 3; $n=11$ ).

Tab. 3: Students' perceptions of progress in oral reading

\begin{tabular}{lllllll}
\hline & \multicolumn{2}{l}{ Initial reading } & \multicolumn{5}{c}{ Final reading } \\
\hline Problems & $\mathbf{V}$ & $\boldsymbol{?}$ & $\mathbf{x}$ & $\mathbf{V}$ & $\boldsymbol{?}$ & $\mathbf{x}$ \\
\hline Intonation and expressiveness & & & & & & \\
$-\quad$ I was not expressive & 3 & 8 & 0 & 0 & 1 & 10 \\
- I read in a low voice & 2 & 7 & 2 & 1 & 0 & 10 \\
\hline
\end{tabular}

Rhythm and punctuation

$\begin{array}{llllllll}- & \text { I did not respect the punctuation } & 4 & 3 & 4 & 0 & 3 & 8\end{array}$

Pronunciation

- I did not say the words well

- I had difficulties pronouncing the words

$\begin{array}{llllll}5 & 6 & 0 & 1 & 2 & 8 \\ 5 & 6 & 0 & 0 & 5 & 6\end{array}$

Fluency

$\begin{array}{lllllllll}- & \text { I did not read the text throughout } & 3 & 4 & 4 & 0 & 4 & 7\end{array}$

$\begin{array}{llllllll}- & 5 & 4 & 2 & 0 & 8 & 3\end{array}$

Understanding

$\begin{array}{llllllll}\text { - I didn't understand the meaning of words } & 4 & 7 & 0 & 0 & 1 & 10\end{array}$

$\begin{array}{lllllll}- & 7 & 3 & 1 & 0 & 1 & 10\end{array}$

$\checkmark-I$ felt this problem a lot / ? - I felt this problem a little / $\mathrm{x}-\mathrm{I}$ didn't feel this problem

(Portfolio: Narrative)

18 The teacher's colleagues, who could not observe the second lesson. 
The class enjoyed these lessons and showed interest in repeating this type of oral reading task. A student who had always failed English in previous years even suggested that the class could stage a play. They also showed metacognitive awareness: they realised that preparation to read was crucial for getting a sense of accomplishment and self-confidence, that difficulties can become positive elements in learning provided that they are aware of them and how to surpass them, and that useful resources can enhance learning and be used in various learning situations.

In reflecting about the experiment, the teachers highlight what they perceived to be its major educational purposes and gains for the students:

Gradually, they liberated themselves and started to look for strategies to solve their difficulties, gaining self-confidence and autonomy in accomplishing, monitoring and evaluating their performance and progress. This interactive strategic learning, as opposed to individualistic and competitive learning, is essential for students to develop cooperation, co-responsibility, self-direction, sharing and negotiation competences, allowing a higher level of commitment to the proposed tasks, making students constructors of knowledge, and respecting their interests and learning pace. (...) This perspective is close to that of critical constructivists who "support the notion that one of the central roles of teaching entails student commitment to the process of knowledge construction" (Kincheloe 2006: 11). For this reason, we believe that this kind of practice dilutes inequalities and injustices in the classroom, paving the way for a democratic and emancipatory school (Zeichner 1993b: 26). (Portfolio: Narrative)

This quotation reveals that as teachers open up opportunities for their students to become critical consumers and creative producers of knowledge, they develop a more critical view of education and start to feel more empowered as agents of change. Although this pedagogical experiment was very small and involved only a few learning tasks, it represented a significant change in the teachers' pedagogical reasoning and pedagogical roles in the classroom. Their students had many difficulties, low self-esteem, and fear of public exposure. The fact that during two classes of 90 minutes they were able to show more self-confidence and willingness to learn, as well as some ability to self-direct their learning and reflect about it, is certainly an important outcome to be considered. The experiment can thus be seen as a case of how small-scale, teacher-led inquiry can promote learner autonomy to some significant extent. It is also an example of how teachers can develop re(idea)alistic practices that explore the space between realities and ideals (Jiménez Raya, Lamb, and Vieira 2007), when they are given the chance to enter that space within a supportive environment. 


\subsection{Relearning to write}

As we have pointed out before, rather than reproducing experience, writing from experience should explore and amplify its meaning, allowing both writers and readers to glimpse the existential structures of experience (van Manen 1990: 127). From this perspective, writing becomes a method of (self)discovery that mediates between living and thinking (Contreras and Pérez de Lara 2010: 81).

These teachers' narrative fluctuates between two types of language. They adopt a hybrid discourse that results from a combination of formal and creative uses of language, which reminds us of the "third idiom" referred to by Shor (1992). They use a more academic-like discourse to present the backstage of pedagogical action (theme, pedagogical choices, context, data collection strategies, conclusions), and a more theatre-like discourse to present action on stage. Actually, the narrative as a whole is conceptualised as a play, as we can see from its title and table of contents, reproduced below with a brief explanation of section contents in brackets:

\section{Oral reading... What's the drama after all?}

Act I - Conspiracy on backstage...

Act II - Preparing the stage set...

[presentation and justification of theme and scope]

[explanation and justification of pedagogical choices]

Act III - ... and assigning roles

[presentation of context and participants]

Act IV - The stage director defines a strategy...

Act $V-$ Raising the curtain...

[summary of teaching and research strategy]

[descriptive-analytical account of pedagogical action, based on observation and data collection]

Act VI-Dropping the curtain...

[final evaluation: outcomes, and implications] 
The title of the narrative - Oral reading... What's the drama after all? - draws on two meanings of "drama" in Portuguese: a theatre play (the case story) and a tragic event (the problems associated with traditional oral reading practices). The Portuguese equivalent to the question raised (“Qual é o drama afinal?”) is used in colloquial speech to mean "What's the big deal?", inducing the idea that oral reading need not be a "tragic event" provided that it is "performed" meaningfully. This idea points out the main outcome of pedagogy for autonomy as pedagogy of possibility - what seemed impossible becomes possible.

The staging metaphor in the title gives prominence to the role of the students as actors and the teacher as stage director. Rather than weakening the role of the teacher, pedagogy for autonomy is seen to strengthen that role $-\mathrm{s} /$ he is no longer a technician; s/he becomes a curriculum designer and a facilitator of learner empowerment. On the other hand, students occupy the central stage of pedagogy, acting from a negotiated script that provides them with both support and opportunities for self-direction. These teachers' play could also be written from a different perspective, where the teacher educator is the stage director and they, together with their students, are the actors. To some extent, case-based pedagogy (and this chapter itself) entails that perspective.

The way classroom action is presented in Act $V$ - Raising the curtain is a good example of the search for a language that reflects the uniqueness of pedagogical experience. Descriptions look like a detailed, vivid play script that allows the reader to picture the scenes on stage and listen to different voices. As in a play script, not everything is revealed: there are a lot of implicit meanings, gaps to fill in, room for imagination and speculation about action.

In writing from experience, one needs to challenge academic modes of writing where the enunciating subject is absent and experience is asphyxiated by an excessive use of classification, categorisation, hierarchisation, and abstraction (Larrosa Bondía 2010). One may need to unlearn what schools and universities often teach us about what counts as legitimate writing: writing that perpetuates modes of knowing that are both domesticated and domesticating, contrary to self-discovery and the problematisation of reality, as if reality were out there to be described as an objective entity separated from our selves (Karlsson 2008). And so, one needs to relearn writing so as to bring it closer to the self and the intellectual and emotional aspects of lived experience.

In presenting and discussing the case developed by these language teachers, we hope to have shown that inquiry and writing from experience can empower teachers to pursue and theorise autonomy in language education. Like Johnson and Golombek (2002: 6) we believe that “teachers' stories of inquiry are not only about professional development; they are professional development." 


\section{Value and shortcomings of experience-based teacher education}

In this final section we summarise gains and shortcomings of the proposed approach, based on the systematic analysis of the teachers' narratives and reflections about case-based pedagogy, participant observation and reflective records of practice, as well as writing about the experience as in the present chapter, which is also a way of figuring out what teacher education practices are about.

Five major gains have been identified as regards teacher empowerment for learner empowerment: agency in professional development, complexified vision of education, reconstruction of pedagogical action, repositioning the self in relation to others, and closeness of language to experience (Vieira 2012: 58-60):

Agency in professional development

- Integration of professional interests in teacher education curricula

- Negotiation of perspectives for understanding and transforming educational experience

- Participation in decision-making about the purposes and processes of change

- Participation in self-evaluation and evaluation of teacher education pedagogy

- Critical stance towards instrumental rationality in teacher education

Complexified vision of education

- Expansion of ethical-conceptual frameworks for analysing educational experience

- Increased awareness of the mismatch between espoused theories and practices

- Increased awareness of historical and structural forces that constrain autonomy

- Resonance of public theories in the reconstruction of personal theories and practices

- Increased tolerance towards uncertainty and ambiguity in educational experience

- Critical stance towards instrumental rationality in school education

Reconstruction of pedagogical action

- Critical analysis of previous educational experience

- Openness to change oriented by democratic values

- Awareness of constraints to change and search of spaces for manoeuvre 
- Development of pedagogical action that challenges established routines

- Valuing learner voices in pedagogical change and inquiry

- Evaluation of the consequences of change upon self and learners

- Acknowledgement of the transitional, incomplete nature of pedagogical action

- View of pedagogical inquiry as a source of valid professional knowledge

Repositioning the self in relation to others

- Expression of personal meanings in the construction of collaborative projects

- Collegial supervision of educational experience and dialogic approach to teaching

- Management of conflict, dissonance, divergence... in the search for understanding

\section{Closeness of language to experience}

- Expansion of educational metalanguage

- Dialogic (de/re)construction of knowledge

- Search for language that 'translates' lived experience

- Development of writing as a method for (self-)understanding

As regards shortcomings, these derive from personal and situational constraints. Case analysis and case construction require a set of conditions that may be difficult to create:

- Use and production of cases that are thought-provoking and can be related to relevant professional experience and theoretical ideas

- Time to explore cases in different directions, using multiple frames of reference

- Expanded contextual and theoretical knowledge to analyse complex educational phenomena

- Articulation of the uniqueness of educational experience with general concepts and principles

- Ability to integrate theory and practice in a rather unpredictable, flexible way

- Ability to conduct a reflective, dialogical approach in the construction of professional knowledge

- Creativity and ingenuity as regards generating and evaluating innovative practices

- Development of inquiry and writing competences (attitudes, knowledge, abilities) 
Even though our approach is directed to in-service teachers, after some adaptations we have more recently started to implement it with pre-service teacher education groups. We encourage them to analyse professional narratives before or during the practicum, to develop case construction in the practicum or to implement small experiments in their supervisors' classes. If learning to teach requires learning to think and to act like a teacher (Kennedy 1999; L. Shulman 1992), then close collaboration among school supervisors, teacher educators and student teachers in case-building would be useful in this respect.

\section{Concluding remarks}

Experience-based teacher education as illustrated above is one of the most important strategies to counteract the divorce between theory and practice, knowing and doing, academic and professional knowledge, research and teaching. In this sense, it may enhance teacher education as a hybrid "third space" (Zeichner 2010b), and also promote an understanding of school pedagogy as "the third margin of the river" (Nóvoa 2011), that is, a place where rigid views of what is and should be done are replaced by exploratory, never-ending journeys of discovery.

However, this kind of approach may go against the grain in professional contexts: schools and teacher education institutions. Teachers often complain that their colleagues are not willing to engage in pedagogical inquiry or even learn about their experiments. On the other hand, teacher educators often work in isolation and their work is undervalued, which also reduces possibilities for collective change. Under these circumstances, the gains from case-based pedagogy are mostly for those who participate directly in it - the teacher educator, the teachers, the students involved in the pedagogical experiments, and perhaps the students that those teachers will teach in the future. Is this good enough? Yes, until we are not able to create better conditions for an inquiry-oriented approach to flourish in teaching and teacher education contexts. If that approach were more familiar than it is, case-based pedagogy would certainly be more easily implemented and would have a larger impact. 